\title{
Efeito da infecção por Actinobacillus pleuropneumoniae nos mecanismos da coagulação do sangue de leitões
}

\section{Effect of Actinobacillus pleuropneumoniae infection on pigs' blood co- agulation system}

\author{
Marcio Manhães Folly ${ }^{1}$, Catherine Kolly ${ }^{2}$
}

\section{Resumo}

O presente trabalho apresenta os resultados do estudo do efeito da infecção causada por Actinobacillus pleuropneumoniae no sistema da coagulação do sangue de leitões.

Vinte e cinco leitões desmamados, isentos de organismos patogênicos específicos, foram separados, ao acaso, em dois grupos. Dez leitões foram infectados com $5 \times 10^{6}$ CFU de A. pleuropneumoniae sorotipo 1, e quinze foram usados como controle negativo.

O tempo parcial ativado de tromboplastina aumentou enquanto que o tempo da protrombina, expressado em porcentagem, diminuiu.

As alterações observadas no tempo de trombina e na quantidade de fibrinogênio estão relacionadas com a formação de fibrina no processo de coagulação. Admitimos que estas observações estejam ligadas ao consumo de fatores de coagulação do sangue nos caminhos intrínsecos, extrínsecos e comuns. Assim, a hemorragia pulmonar e a formação de coágulos, que são características da fase aguda dessa doença, podem ser explicadas.

Palavras chave: Actinobacillus pleuropneumoniae; pleuropneumonia; fator de coagulação sangüínea

\section{Introdução}

A pleuropneumonia dos suínos é causada pela bactéria Gram negativa Actinobacillus pleuropneumoniae. $\mathrm{Na}$ moderna indústria de criação suína, o risco de infecção aumenta com o estresse, com problemas relacionados com o manejo e com a introdução de animais enfermos nos plantéis.

A A. pleuropneumoniae tem sido observada em vários países onde a suinocultura é realizada de forma muito intensiva como Estados Unidos, Canadá, México, alguns países da América do Sul (dentre eles o Brasil), Austrália, Japão, Taiwan e grande parte da Europa (Sebunya e Saunders, 1983).

$\mathrm{Na}$ forma superaguda, os porcos demonstram alta temperatura $\left(41.5-42^{\circ} \mathrm{C}\right)$, anorexia, tosse, dispnéia, estado de choque com corrimento nasal sanguinolento e, finalmente, morte. Na forma aguda, há febre $\left(40.5-41^{\circ} \mathrm{C}\right)$, tosse e dispnéia. Na forma crônica, que pode suceder à forma aguda, são observadas diminuição do ganho de peso e tosse persistente.

Os achados anátomo-patológicos causados por $A$. pleuropneumoniae, são caracterizados por pleurite fibrinosa generalizada, pneumonia necrosante fibrino hemorrágica dos lobos apicais, cardíacos, diafragmáticos e intermediários (Nicolet e Koenig, 1966).

O aumento da atividade dos macrófagos alveolares dos leitões infectados com A. pleuropneumoniae foi demonstrado por Caruso e Ross (1990). A estimulação de polimorfonucleares pela endotoxina, direta e indiretamente, através de fator de tumor necrosante alfa (FNT $\alpha$ ) e interleucina 8 (IL-8) liberados dos macrófagos, levam à liberação de enzimas proteolíticas lisossomais que contribuem para a degradação de proteínas do interstício pulmonar e podem modular a deposição de fibrina alveolar através da digestão de proteínas da coagulação (Seymour et al., 1986; Colditz et al., 1989).

Os mecanismos da coagulação e as propriedades anticoagulantes no sangue e suas interações com o sitema imunológico podem ser descritos como a catalização da trombina sobre o fibrinogênio (FIB) transformando-o em fibrina. Além disso a trombina forma um complexo com a trombomodulina (proteína de superfície das células endoteliais). Este complexo ativa a proteína $\mathrm{C}$ que age como anticoagulante através da degradação dos fatores de coagulação sangüínea V e VII. A ação da endotoxina, interleucina-1 (IL-1) e o FNT $\alpha$ sobre as células endoteliais alterando a trombomodulina foi descrita por Moore et al. (1987). A trombina aumenta a aderência dos polimorfonucleares ao endotélio e estimula a produção de anions superóxido e de elastase (enzima proteolítica lisossomal) que degrada os fatores de coagulação fibrinogênio V, VIII, XII e XIII (Vercelotti et al., 1989).

A adesão e $o$ aumento da atividade dos neutrófilos produzindo radicais de oxigênio e peróxido de hidrogênio e outros radicais de metabolismo, conduzem a uma lesão das paredes dos vasos sangüíneos.

1. Universidade Estadual do Norte Fluminense, Av. Alberto Lamego 2000, 28015-620 Campos dos Goytacazes, RJ, Brasil

2. Centro de Pesquisa Agrícola, CIBA GEIGY, CH1566 St-Aubin, Switzerland 
Estudos preliminares demonstraram uma prolongação do tempo de protrombina (TP) e do tempo parcial ativado de tromboplastina (TPAT) durante a forma aguda da pleuropneumonia em porcos infectados com várias doses de $A$. pleuropneumoniae indicando alterações no mecanismo de coagulação do sangue dos leitões (Folly et al., 1991).

O objetivo deste trabalho foi demonstrar o efeito do $A$. pleuropneumoniae nos mecanismos que envolvem a coagulação do sangue.

\section{Material e Métodos}

Foram utilizados 25 leitões desmamados, isentos de organismos patogênicos específicos, da raça Large White, pesando entre 20 e $25 \mathrm{~kg}$, de ambos sexos, que foram divididos ao acaso em dois grupos. O grupo 1, com 15 leitões, foi considerado como controle negativo e os animais não foram infectados; o grupo 2, com 10 leitões, foi infectado com $A$. pleuropneumoniae.

Antes do início do experimento os leitões foram colocados num sistema de isolamento, durante uma semana, para aclimatação ao novo ambiente.

O sorotipo 1 da bactéria $A$. pleuropneumoniae, foi obtido da Veterinary Infectious Disease Organization, University of Saskatchewan, Saskatoon, Canadá e cultivado em infusão de cérebro e coração + polivitamina (Polyvitex, Bio Merieux, France) + fator V de crescimento bacteriano (Taxo V, Becton-Dickinson, Cockeysville, USA) e incubado a $37^{\circ} \mathrm{C}$ por $24 \mathrm{~h}$.

O grupo 2 foi infectado utilizando-se uma câmara aerosol com um nebulizador, (Ultra Neb 99 De Villbis GMBH, West Germany), segundo o método preconizado por Osborne et al. (1985). O inóculo foi preparado de uma suspensão de bactérias correspondendo a $5 \times 10^{6} \mathrm{CFU}$ em $200 \mathrm{ml}$ de PBS (0.1 M fosfato, $0.15 \mathrm{M} \mathrm{NaCl}, \mathrm{pH}$ 7.2) com $10 \%$ de soro fetal de bezerro; a exposição à infecção durou $10 \mathrm{~min}$. Após a infecção a temperatura foi medida diariamente e os sinais clínicos da pleuropneumonia (anorexia, tosse, dispnéia, hipertemia e epistaxis) foram registrados nos animais doentes. A necrópsia foi realizada em todos os leitões que vieram a falecer.

As amostras de sangue foram coletadas em Vacutainer (Becton-Dickson, Basiléia, Suíça) com $0,5 \mathrm{ml}$ de citrato de sódio $(0,129 \mathrm{M}$ para os testes de coagulação) e centrifugadas por $15 \mathrm{~min}$. a $3000 \mathrm{rpm}$ na temperatura de $5^{\circ} \mathrm{C}$. A concentração do FIB foi determinada pelo método de Clauss modificado. O plasma dos leitões foi diluído na proporção de 1:5 com o tampão Michaelis "Roche". Desta solução, $0,2 \mathrm{ml}$ foram pré-aquecidos por $2 \mathrm{~min}$. em cubetas do aparelho Cobas Fibro; após $0,2 \mathrm{ml}$ do reagente trombina (Roche-Cobas Fibro 60NIH U/ml) foram adicionados e o ponto final de coagulação foi determinado segundo as instruções dos fabricantes (Cobas Fibro Machine Hoffmann La Roche, Basiléia, Suíça). O tempo de trombina (TT) foi determinado com o reagente de trombina "Roche" diluído na proporção de 1:7,5 em água destilada. Foram incubados $0,2 \mathrm{ml}$ de plasma de leitão em cubetas Cobas Fibro pré-aquecidas a $37^{\circ} \mathrm{C}$ por $2 \mathrm{~min}$. Foram adicionados no plasma $0,2 \mathrm{ml}$ do reagente trombina e o ponto de coagulação foi determinado segundo as instruções do Cobas Fibro Machine. Para o TPAT, $0,1 \mathrm{ml}$ de plasma de leitão foi incubado com $0,1 \mathrm{ml}$ de reagent PTT "Roche" em temperatura ambiente por $3 \mathrm{~min}$. dentro das cubetas do Cobas Fibro; logo após, $0,1 \mathrm{ml}$ de cloreto de cálcio $(0,025 \mathrm{~mol} / \mathrm{l})$ pré-aquecido a $37^{\circ} \mathrm{C}$ foi adicionado e o tempo de coagulação foi determinado usando-se as instruções do fabricante do Cobas Fibro. O TP foi determinado com o reagente tromboplastina "Roche" calibrado com cérebro de coelho (CRB) e dissolvido em $10 \mathrm{ml}$ de água destilada. Um volume de $0,1 \mathrm{ml}$ de plasma de leitão foi colocado em cubetas Cobas Fibro a $37^{\circ} \mathrm{C}$ por 2 min. e em seguida $0,2 \mathrm{ml}$ de reagente tromboplastina CRB foram adicionados; o tempo de coagulação foi determinado, em variações percentuais, segundo as instruções para o Cobas Fibro.

A média e o desvio padrão do erro da média (SEM) foram calculados com o programa Symphony (Lotus Development Corporation, Cambridge, USA). O teste T de Student foi também utilizado para comparar resultados entre o grupo infectado e o não infectado.

\section{Resultados}

Todos os leitões do grupo infectado demonstraram sinais clínicos de pleuropneumonia, [anorexia, tosse, dispnéia, hipertemia $\left(40.4^{\circ} \mathrm{C} \pm 0.28\right)$ e epistaxe].

No grupo não infectado não houve mortalidade, porém, no infectado houve $60 \%$ durante o experimento. Os achados nos leitões mortos, no grupo infectado, foram: cianose com escorrimento nasal; traquéia e laringe com sangue; pulmões edemaciados, firmes, hemorrágicos e com coágulos nos lobos apicais, cardíacos, diafragmáticos e intermediários, além de pleurite fibrinosa.

A A. pleuropneumoniae foi detectada pelas análises bacteriológicas nos pulmões de todos os leitões mortos.

Uma diminuição progressiva do TP foi observada no grupo infectado demonstrando alterações no mecanismo extrínseco da coagulação sangüínea. No grupo não infectado não houve alteração (Fig. 1).

Observou-se um aumento progressivo do TPAT (Fig. 2) $20 \mathrm{~h}$ depois da infecção no grupo infectado; no grupo controle não houve alterações.

Não houve diminuição no TT no grupo não infectado durante o experimento, porém no grupo infectado observou-se uma diminuição do tempo a partir de $20 \mathrm{~h}$ após a infecção (Fig. 3).

Um aumento progressivo na concentração de FIB foi observado 20 h depois da infecção no grupo infectado, permanecendo elevado até o fim do experimento (Fig. 4). 


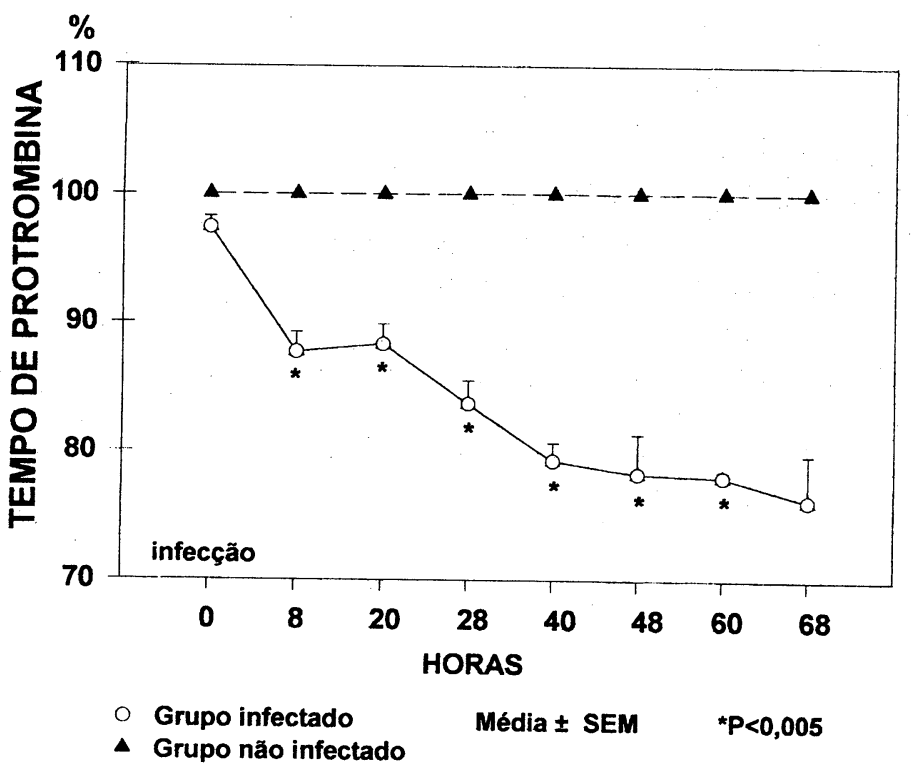

Figura 1 - Diminuição (em porcentagem) no tempo de protrombina nos animais infectados.

*Diferenças significantes $(P<0.005)$ foram observadas entre os grupos infectado e não infectado.

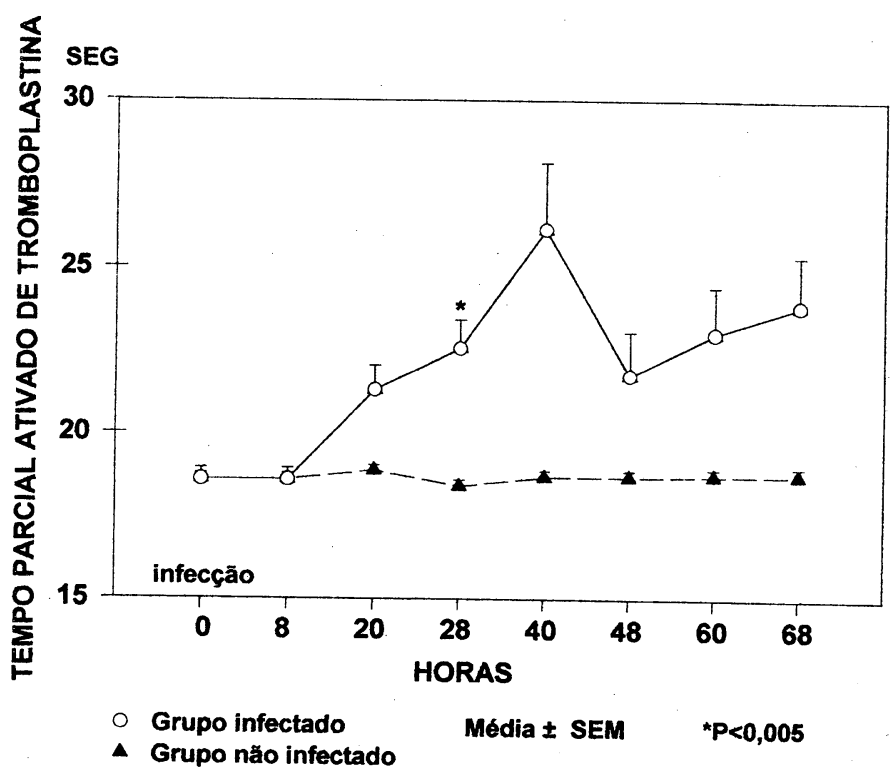

Figura 2 - Aumento no tempo parcial ativado de tromboplastina nos animais infectados.

*Diferenças significantes $(P<0.005)$ foram observadas entre os grupos infectado e não infectado.

\section{Discussão}

A A. pleuropneumonia, sorotipo 1, produziu sinais clínicos e mortalidade. As alterações anátomo-patológicas foram pleurite e pneumonia hemorrágica. Esse distúrbio circulatório pode ser explicado pelo que demonstrou Bertram (1985): os primeiros efeitos da infecção por $A$.

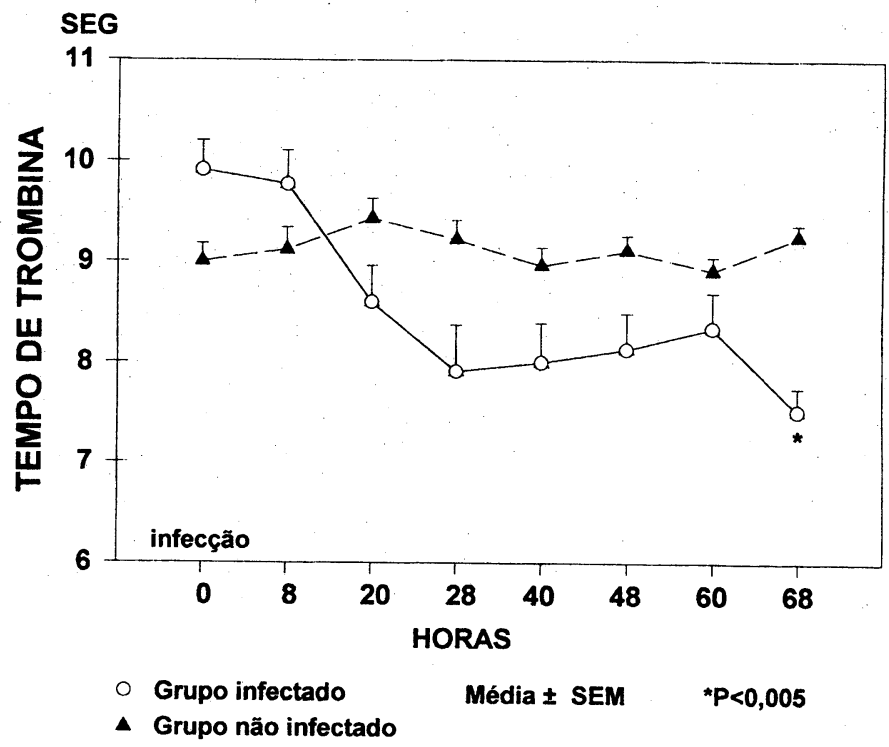

Figura 3 - Diminuição no tempo de trombina nos animais infectados. *Diferenças significantes $(P<0.005)$ foram observadas entre os grupos infectado e não infectado.

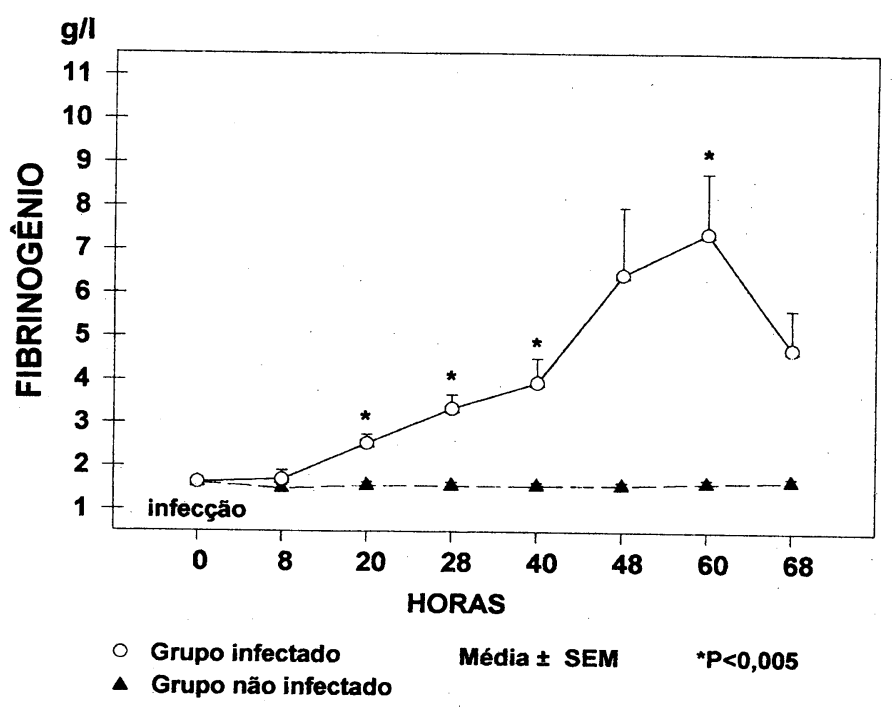

Figura 4 - Aumento na concentração de fibrinogênio durante o experimento nos animais infectados.

*Diferenças significantes $(\mathrm{P}<0.005)$ foram observadas entre os grupos infectado e não infectado.

pleuropneumoniae envolviam ativação de macrófagos e plaquetas e um aumento da permeabilidade dos capilares do septo intralveolar.

A ativação da coagulação do sangue leva a uma diminuição da concentração dos fatores e cofatores do mecanismo intrínseco (XII, XI, IX, VIII) e do mecanismo extrínsico (fator VII e tromboplastina tecidual). Os fatores ativados 
IXa, VIIla do caminho intrínseco da coagulação formam um complexo juntamente com fosfolipídeos e cálcio no qual ativa o fator $X$ do caminho comum da coagulação sangüínea; por outro lado, o fator VII ativado forma um complexo com a tromboplastina tecidual e cálcio que também ativa o fator $X$. $O$ fator $X$ ativado juntamente com o fator $V$ ativado, fosfolipídeos e cálcio formam um complexo que transforma a protrombina em trombina e esta última catalisando a transformação do FIB em fibrina leva à formação do coágulo (Duckert, 1984).

$O$ aumento do TPAT demonstrou que os fatores e cofatores do mecanismo intrínseco da coagulação sangüínea foram ativados. Essas observações puderam ser explicadas por Movat e Burrowes (1985) que descreveram os efeitos da endotoxina na reação inflamatória local, incluindo a estimulação de neutrófilos e macrófagos e a ativação do fator XII do mecanismo intrínseco. Mais tarde, Simon e Ward (1988) relataram a importância da endotoxina, o sistema do complemento, metabólitos do ácido araquinódico e do sistema de coagulação sangüínea nas lesões pulmonares.

Um aumento na produção de tromboplastina tecidual pelas células inflamatórias, especialmente macrófagos alveolares e células endoteliais estimuladas pela endotoxina e complexos imunes, contribuem para a atividade procoagulante conduzindo a uma diminuição do fator VII do mecanismo extrínseco da coagulação do sangue (Car, 1990). Essa descrição pode estar relacionada com a diminuição do TP observada nesse estudo que reflete consumo de fatores e cofatores do caminho extrínseco da coagulação sangüínea.

Endotoxina, citocinas como IL-1 e FTN $\alpha$ agem sobre as células endoteliais suprimindo a atividade da trombomodulina (Jaffe, 1988). Conseqüentemente uma diminuição do complexo trombina e trombomodulina leva a um aumento na concentração de trombina no sangue. Em adição, a ativação dos mecanismos extrínseco e intrínseco da coagulação leva também a um aumento da concentração de trombina. Uma diminuição no TT foi observada durante o experimento refletindo um aumento na concentração sangüínea da trombina. A hiperfibrinogenia observada pode ser explicada pelo aumento da produção hepática durante o processo inflamatório agudo. Um aumento das concentrações de trombina e de FIB no sangue reflete um aumento nas concentrações de monômeros de fibrina, fibrinopepitídeos $A$ e $B$ os quais resultam na formação de coágulo. Essas alterações foram observadas macroscopicamente nos pulmões dos leitões infectados $\operatorname{com}$ A. pleuropneumoniae.

Conclui-se que a bactéria $A$. pleuropneumoniae produziu a ativação dos fatores dos caminhos extrínsecos, intrínsecos e comuns da coagulação do sangue através dos mediadores inflamatórios. Essas ativações podem contribuir para o aumento da concentração de trombina levando a transformação do FIB em fibrina. As lesões pulmonares associadas com coágulos sangüíneos nos ani- mais infectados com $A$. pleuropneumoniae e que são caraterísticas dessa enfermidade, podem ter sido uma das conseqüências da ativação e consumo de fatores e cofatores da coagulação do sangue.

\section{Abstract \\ Effect of Actinobacillus pleuropneumoniae infection on pigs' blood coagulation system}

The effect of Actinobacillus pleuropneumoniae infection on pigs' blood coagulation system was studied. Twenty five specific pathogen free weaned piglets were randomly assorted into two groups. Ten of the piglets were infected with $5 \times 10^{6} \mathrm{CFU}$ of $A$. pleuropneumoniae serotype 1 , and 15 used as negative controls.

The prothrombin time, expressed as percentage, decreased. The activated partial thromboplastin time increased and the thrombin time decreased. Concentrations of fibrinogen increased during the trial. These observations were consistent with consumptions of blood coagulation factors in the intrinsic, extrinsic, and common pathways of blood coagulation, producing coagulability. Therefore intrapulmonary haemorrhage and clot formation may be observed in the lungs of piglets infected with $A$. pleuropneumoniae.

Key words: Actinobacillus pleuropneumoniae; pleuropneumonia; blood coagulation factors

\section{Referências bibliográficas}

BERTRAM, T. A. Quantitative morphology of peracute pulmonary lesions in swine induced by Haemophilus pleuropneumoniae. Vet. Pathol., v. 22, p. 598-609, 1985.

CAR, B.D. The pathogenesis of fibrin deposition in pneumonic pasteurellosis. Thesis, University of Cornell, USA, 1990.

CARUSO, J. P., ROSS, R.F. Effects of Mycoplasma hyopneumoniae and Actinobacillus pleuropneumoniae infections on alveolar macrophages functions in swine. Am. J. Vet. Research, v. 51, p. 227-231, 1990.

COLDITZI., ZWAHLEN R., DEWALD B., BAGGIOLINI M. In vivo inflammatory activity of neutrophil-activating factor, a novel peptide derived from human monocytes. Am. J. Pathol., v. 134, p. 755-760, 1989.

DUCKERT, F. Blood Coagulation and Fibrinolysis. Geigy Scientific Tables, v. 3, p. 222-235, 1984.

FOLLY, M., KOLLY, C., MARTINOD, S. Coagulation induced by challenge with various doses of Actinobacillus pleuropneumoniae. Vet. Record, v. 128, p. 186-187, 1991.

JAFFE, E.A. Endothelial cells, inflammation: basic principles and clinical correlates, New York. Raven Press, 1988. p. 559-576.

MOORE, K.L., ANDREOLI, S.P., ESMON, N.L., ESMON, C.T., BANG, N.U. Endotoxin enhances tissue factor and supresses thrombomodulin expression of human vascular endothelium in vitro. J. Clin. Investigation, v. 79, p. 124-130, 1987.

MOVAT, H. Z., BURROWES, C. E. The local Schwartzmann reaction endotoxin mediated inflamatory and thrombo- 
hemorrhagic lesion. Handbook of Endotoxin, v. 3, p. 260302, 1985.

NICOLET, J., KOENIG, H. Zur Haemophilus pleuropneumoniae beim Schwein. Bakteriologische, pathologish, anatomische und histologische Befunde. Pathol. Microbiol., v. 29, p. 301-306, 1966.

OSBORNE, A.D., SAUNDERS, J.R., SEBUNYA, T.K., WILSON, P., GREEN, G. H. A simple aerosol chamber for experimental reproduction of respiratory disease in pigs and other species. Can. J. Comp. Med., v. 49, p. 434-435, 1985.

SEBUNYA T.N.K., SAUNDERS J.R. Haemophilus pleuropneumoniae infection in swine: a review. J.A.V.M.A., v. 182, p. 1331-1337, 1983.
SEYMOUR J.K., VADAS M.A., HARLAN J.M., SPARKS L.H., GAMBLE J.R., AGOSTI J.M., WALTERS A. M. Stimulation of neutrophils by tumor necrosis factor. J. Immunol., v.136, p. 4220-4225, 1986.

SIMON, R.H., WARD, P.A. Adult respiratory distress syndrom inflammation: basic principles and clinical correlates. New York. Raven Press, 1988. p. 815-827.

VERCELOTTI G.M., WICKHAM N.W.R., GUSTAFSON K.S., YIN H.Q., HERBERT M., JACCOB H.S. Thrombin-treated endothelium primes neutrophil functions: inhibition by platelets-activating factor receptor antagonists. J. Leuk. Biol., v. 45, p. $483-490,1989$. 